\title{
Asthma quality of life during 1 year of treatment with budesonide with or without formoterol
}

\author{
E.F. Juniper*, K. Svensson**, P.M. O'Byrne ${ }^{+}$, P.J. Barnes ${ }^{++}$, C-A. Bauer**, C-G.A. Löfdahl", \\ D.S. Postma ${ }^{+}$, R.A. Pauwels ${ }^{\$}$ A.E. Tattersfield ${ }^{\S}$, A. Ullman
}

Asthma quality of life during 1 year of treatment with budesonide with or without formoterol. E.F. Juniper, K. Svensson, P.M. O'Byrne, P.J. Barnes, C-A. Bauer, C-G.A. Löfdahl, D.S. Postma, R.A. Pauwels, A.E. Tattersfield, A. Ullman. (C) ERS Journals Ltd 1999.

ABSTRACT: The Formoterol and Corticosteroids Establishing Therapy (FACET) study has provided the first opportunity to examine the long-term effects of inhaled steroids and long-acting $\beta_{2}$-agonists on asthma-specific quality of life. The objectives of the present study were to: evaluate the effects of long-term $(1 \mathrm{yr})$ formoterol and increasing doses of budesonide on asthma quality of life; 2 ) to determine whether initial improvements in quality of life are sustained when improvements in clinical indices persist; and 3) to evaluate the long-term relationship between changes in clinical indices and changes in quality of life.

Of the 852 asthmatic adults enrolled, 470 from five countries participated in this quality of life evaluation. After a 4-week run-in on 1,600 $\mu \mathrm{g}$ budesonide, patients were randomized to either $200 \mu \mathrm{g}$ (Bud200) or $800 \mu \mathrm{g}$ budesonide (Bud800) in combination with either $24 \mu \mathrm{g}$ formoterol (F) or placebo daily for $1 \mathrm{yr}$. The Asthma Quality of Life Questionnaire (AQLQ) was completed and conventional clinical indices measured at enrolment and randomization and on seven occasions during the following 12 months.

During the run-in, there was an improvement in AQLQ score (changes $(\Delta)$ in overall score $\approx 0.50 ; p<0.0001)$. After randomization, there was a further improvement in the Bud800+F group $(\Delta=0.21 ; \mathbf{p}=0.028)$. One month post-randomization, improvements in all groups stabilized and were sustained throughout the 12 months in a pattern very similar to that observed for the conventional clinical indices. The correlation of individual patient changes in clinical indices and changes in AQLQ score during the 12-month randomized period were weak to moderate (maximum $\mathbf{r}=\mathbf{0 . 5 1}$.

Improvements in quality of life, which were greatest in the $800 \mu$ g budesonide plus $24 \mu \mathrm{g}$ formoterol group, were sustained throughout the 12 months in a similar manner to the clinical indices. Long-term changes in conventional clinical indices cannot be used to predict the effect of treatment on individual patient experience.

Eur Respir J 1999; 14: 1038-1043.

The primary hypothesis tested in the Formoterol and Corticosteroids Establishing Therapy (FACET) study was that the addition of regular treatment with the long-acting inhaled $\beta_{2}$-agonist, formoterol, to a lower and higher dose of the inhaled glucocorticosteroid budesonide would result in improved control of symptoms and lung function, without any long-term deterioration in the control of asthma over a 12-month period [1]. The results showed that the addition of formoterol to both doses of inhaled steroid improved asthma symptoms and resulted in a decrease in the rate of severe and mild asthma exacerbations.

A secondary objective of the FACET study was to determine the effect of these interventions on health-related quality of life (HRQL). Although short-term studies have shown that both inhaled steroids and long-acting $\beta_{2}$-agonists are associated with an improvement in asthma-specific quality of life [2-8], there have been no longer-term studies $(\geq 1 \mathrm{yr})$ of these interventions. As a result, the question has arisen as to whether the initial improvements in
*Dept of Clinical Epidemiology \& Biostatistics, McMaster University, Hamilton, Canada. **Astra Draco AB, Lurid, Sweden. ${ }^{+}$Dept of Medicine, McMaster University, Hamilton, Canada. ${ }^{++}$Dept of Thoracic Medicine, The National Heart and Lung Institute, London, U.K. " Dept of Respiratory Medicine, Lurid University Hospital, Lund, Sweden. ${ }^{\dagger}$ Dept of Pulmonology, University Hospital, Groningen, the Netherlands. Dept of Respiratory Diseases, University Hospital, Ghent, Belgium. ${ }^{\S}$ Respiratory Medicine Unit, City Hospital, Nottingham, U.K.

Correspondence: E. Juniper, Dept of Clinical Epidemiology and Biostatistics, McMaster University Medical Centre, 1200 Main Street West, Hamilton, Ontario L8N 3Z5 Canada. Fax: 19055770017

Keywords: Asthma

budesonide

formoterol

quality of life

Received: January 11999

Accepted after revision July 71999

Supported by Astra Draco AB, Sweden.
HRQL are sustained in the same manner as the clinical indices or whether there is an initial euphoric period, or "honeymoon", followed by a deterioration. In addition, there is no evidence regarding whether or not the longterm changes in conventional clinical measures can be used to infer the functional changes experienced by patients.

This study addresses all three questions in a subgroup of patients in whom asthma-specific quality of life was measured.

\section{Materials and methods}

\section{Patients}

Patients from five of the nine countries (Belgium, Canada, Luxembourg, the Netherlands and the UK) participating in the FACET study were assessed for 
HRQL. The restriction to these countries was due to the availability of validated translations of the Asthma Quality of Life Questionnaire (AQLQ) at the start of the study.

In order to be included in the run-in period, patients were required to have current asthma according to the American Thoracic Society definition and to have used inhaled glucocorticosteroids for $\geq 3$ months (maximum daily dose: 2,000 $\mu \mathrm{g}$ beclomethasone dipropionate or $1,600 \mu \mathrm{g}$ budesonide via pressurized metered-dose inhaler $800 \mu \mathrm{g}$ budesonide via Turbuhaler ${ }^{\circledR}$ (AstraZeneca, Södertälje, Sweden) or 800 $\mu \mathrm{g}$ fluticasone propionate). They were required to be $18-70$ yrs of age and to have forced expiratory volume in one second (FEV1) of $\geq 50 \%$ of the predicted value with a $\geq 15 \%$ increase in FEV1 after inhalation of $1 \mathrm{mg}$ terbutaline. To qualify for randomization, patients had to have been compliant within $75-125 \%$ of the prescribed dose of budesonide throughout the run-in period and to have had stable asthma during the last 10 days of the run-in period. Instability was defined as fulfilling one or more of the following criteria: diurnal variation in peak expiratory flow (PEF) $\geq 20 \%$ on two consecutive days, $\beta_{2}$-agonist use $\geq 8$ inhalations. $24 \mathrm{~h}^{-1}$ on two consecutive days, wakening due to asthma on two consecutive nights, and clinical need for oral steroids. Patients with medical conditions that might have an impact on quality of life or interfere with the trial interventions were excluded from the study.

\section{Study design}

The design of this study has been reported in detail elsewhere [1]. In summary, it was a double-blind randomized parallel-group study with four treatment groups. Enrolled patients entered a 4-week run-in period during which they took inhaled budesonide (Pulmicort ${ }^{\mathrm{R}}$; AstraZeneca) $800 \mu \mathrm{g}$ twice daily. This was to ensure that asthma was as well controlled and stable as possible at randomization. Patients who did not fulfil the criteria for stable asthma or were noncompliant were withdrawn after the run-in period. Patients who met the criteria were randomized to receive one of four treatments, twice daily, for a period of 12 months: $100 \mu \mathrm{g}$ budesonide+placebo (Bud200), $100 \mu \mathrm{g}$ budesonide $+12 \mu \mathrm{g}$ formoterol (F) (Oxis $\left.{ }^{\mathrm{R}}\right)(\mathrm{Bud} 200+\mathrm{F})$, $400 \mu \mathrm{g}$ budesonide+placebo (Bud800), or $400 \mu \mathrm{g}$ budesonide $+12 \mu \mathrm{g}$ formoterol (Bud800+F) (fig. 1). Throughout the study, inhaled terbutaline (Bricanyl ${ }^{\circledR}$ (AstraZeneca)), $250 \mu \mathrm{g}$ per dose, was used as rescue medication. All medications were given via the dry powder inhaler Turbuhaler ${ }^{\circledR}$, and all doses refer to metered dose.

Patients attended the clinic nine times during the study (at the beginning of the run-in and after 0, 0.5, 1, 2, 3, 6, 9 and 12 months). On each occasion they completed the Asthma Quality of Life Questionnaire (AQLQ) $[9,10]$ and prebronchodilator spirometry (FEV1\% pred) was performed. Daily throughout the study, patients kept a diary in which they made recordings of PEF, asthma symptoms and rescue medication use.

\section{Outcome measures}

Asthma Quality of Life Questionnaire. HRQL was assessed at the beginning of each clinic visit using the selfadministered version of the AQLQ $[9,10]$. The 32-item

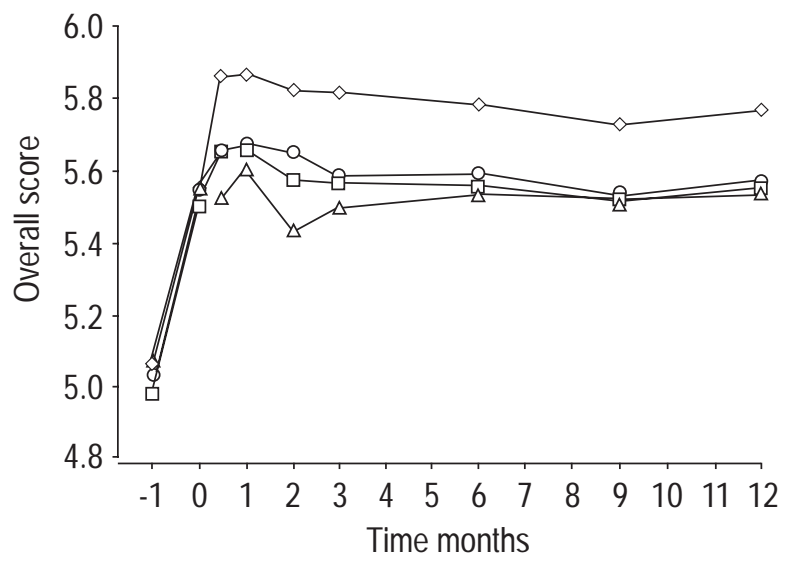

Fig. 1. - Overall Asthma Quality of Life Questionnaire score by treatment and visit. Data are presented as means. $\triangle: 200 \mu \mathrm{g}$ budesonide daily (Bud200); $\bigcirc: 800 \mu \mathrm{g}$ budesonide daily (Bud800); $\square: \operatorname{Bud} 200+24$ $\mu \mathrm{g}$ formoterol $(\mathrm{F}) ; \diamond: \operatorname{Bud} 800+\mathrm{F}$.

AQLQ assesses the functional impairments that are most troublesome to adults with asthma. Patients are asked to recall their experiences during the previous 2 weeks and to respond to each question on a seven-point interval scale ( $1=$ severe impairment to $7=$ no impairment $)$. The questions are grouped into four domains: activity limitations (11 items), symptoms (12 items), emotional function (five items) and environmental stimuli (four items). Domain scores as well as an overall score are calculated from the unweighted means of item scores.

Patient diary. Each morning and evening, patients scored the severity of their asthma symptoms using the following scale: $0=$ none, $1=$ mild, $2=$ moderate, and $3=$ severe. Morning and evening scores were added to form a daily asthma symptom variable, ranging 0-6. Patients recorded PEF every morning and evening throughout the study.

\section{Analysis}

For diary variables, the mean values for the last 10 days before each visit were used in the analysis. For dealing with missing AQLQ data, the following rule was adopted: values for each domain were calculated provided at least two-thirds of the items were scored, otherwise the domain value was set to missing. If any domain score was missing, the overall AQLQ score was set to missing. The frequency of missing values was low, $\approx 0.8 \%$ for the symptom, emotional and environmental domains. For the activity domain, it was higher, at $3.2 \%$, due to either misunderstanding of or an inability to identify patient-specific activities.

Data were analysed using a two-by-two factorial design. The analysis was based on an "all randomized patients" approach. The applied model was an analysis of covariance model with country as a blocking factor and the baseline value as a covariate. Adjusted means from this analysis of the change during the treatment period and the corresponding $95 \%$ confidence intervals are reported for each of the four treatment groups. Associations between change in AQLQ scores between randomization (visit 2) 
Table 1. - Demographic and baseline data at visit 1

\begin{tabular}{lcccc}
\hline & \multicolumn{3}{c}{ Treatment group } \\
\cline { 2 - 5 } & Bud200 & Bud200+F & Bud800 & Bud800+F \\
\hline Patients n & 118 & 116 & 115 & 117 \\
Age yrs & 42 & 42 & 44 \\
Sex M/F & $58 / 60$ & $60 / 56$ & $57 / 58$ & $48 / 69$ \\
Height cm & 172 & 170 & 170 & 172 \\
Inhaled steroids at enrolment mg.day ${ }^{-1}$ & 795 & 725 & 740 & 765 \\
Asthma Quality of Life & & & 5.03 \\
Overall & 5.08 & 5.98 & 5.09 & 5.16 \\
Symptoms & 5.19 & 5.07 & 5.19 & 5.17 \\
Emotions & 5.38 & 4.20 & 5.02 & 4.03 \\
Activities & 4.72 & 4.71 & 4.69 & 4.74 \\
Environment & & & \\
\hline
\end{tabular}

Bud200: $200 \mu \mathrm{g}$ budesonide daily; Bud800: $800 \mu \mathrm{g}$ budesonide daily; F: $24 \mu \mathrm{g}$ formoterol daily; M: male; F: female.

and the end of study (visit 9) and change in conventional clinical indices between these visits were examined using the Pearson correlation coefficient.

\section{Results}

Of the 852 patients randomized in the FACET study, 470 were eligible for HRQL assessment. Four patients did not fill in the AQLQ questionnaire at baseline and were excluded from the analysis. Thus, the analysis set consists of 466 patients. Demographic and baseline data for this subset of patients are shown in tables 1 and 2 . These values are in very close agreement with those found for the total FACET population [1]. The full 12 months of the study was completed by 356 patients. Reasons for dropout were proportionally the same as for the full population $[1]$.

AQLQ results are presented in figures 1 and 2. During the run-in period, there was an improvement in quality of life in all domains and in overall score. The improvements were all statistically significant $(\mathrm{p}<0.0001)$ with a change in mean score of $\approx 0.50$. Following randomization, there was a further improvement in the highest dose group, Bud800+F, (change $(\Delta)$ in overall score $=0.21$; $\mathrm{p}=0.028)$. After the first month, scores in all four groups were maintained at approximately the same level during the entire 12-month treatment period; there was no evidence of deterioration.

FEV1 (\% pred) values are shown in figure 3 and represent the pattern of treatment response observed in the other clinical indices [1]. During the run-in period, FEV1 increased by $>5 \%$; during the randomized period, it further improved in the two groups receiving formoterol. One month post-randomization, all groups settled and showed a steady-state pattern for the rest of the treatment period. This pattern, in this subgroup of 466 patients, is almost identical to that which was seen for the entire group of 852 FACET patients [1]. Morning PEF, symptom scores and rescue medication use at the start and end of the run-in and after 12 months of treatment are shown in table 2 .

Although the patterns of mean responses for AQLQ scores and for the clinical variables were very similar (figs. 1-3), correlations between change in AQLQ scores and change in clinical measures over the randomized period were only weak to moderate (table 3 , fig. 4).

\section{Discussion}

This is the first study to explore the long-term effects of interventions on HRQL in patients with asthma. The results show that the mean HRQL data for each treatment group followed a very similar pattern to those seen in the conventional clinical indices, such as FEV1 and PEF. There was an improvement in both overall quality of life and each domain of the AQLQ (symptoms, activity limitation, emotional function and environmental exposure) during the run-in period, when all subjects were treated with high-dose budesonide. This improvement was of a

Table 2. - Clinical measures

\begin{tabular}{|c|c|c|c|c|c|}
\hline & \multirow[b]{2}{*}{ Visit } & \multicolumn{4}{|c|}{ Treatment group } \\
\hline & & Bud200 & Bud200+F & Bud800 & Bud $800+F$ \\
\hline \multirow[t]{3}{*}{ FEV1 \% pred } & 1 & 76.0 & 76.1 & 74.9 & 76.4 \\
\hline & 2 & 80.8 & 82.8 & 80.9 & 81.2 \\
\hline & 9 & 78.4 & 83.7 & 79.5 & 85.1 \\
\hline \multirow[t]{2}{*}{ Rescue medication puffs } & 2 & 1.00 & 0.98 & 1.08 & 0.83 \\
\hline & 9 & 1.42 & 0.85 & 1.17 & 0.47 \\
\hline \multirow[t]{2}{*}{ Diary symptom score* } & 2 & 0.98 & 1.05 & 0.97 & 1.02 \\
\hline & 9 & 1.14 & 0.99 & 1.01 & 0.70 \\
\hline \multirow[t]{2}{*}{ Morning PEF $\mathrm{L} \cdot \mathrm{min}^{-1}$} & 2 & 397 & 399 & 379 & 407 \\
\hline & 9 & 383 & 408 & 377 & 434 \\
\hline
\end{tabular}

Data are presented as means. *: on 0-6 scale. Visit 1: beginning of the 4-week run in; Visit 2: randomization at 0 months; Visit 3: end of study at 12 months. Bud200: $200 \mu \mathrm{g}$ budesonide daily; Bud800: $800 \mu \mathrm{g}$ budesonide daily; F: $24 \mu \mathrm{g}$ formoterol daily; FEV1: forced expiratory volume in one second; PEF: peak expiratory flow. 

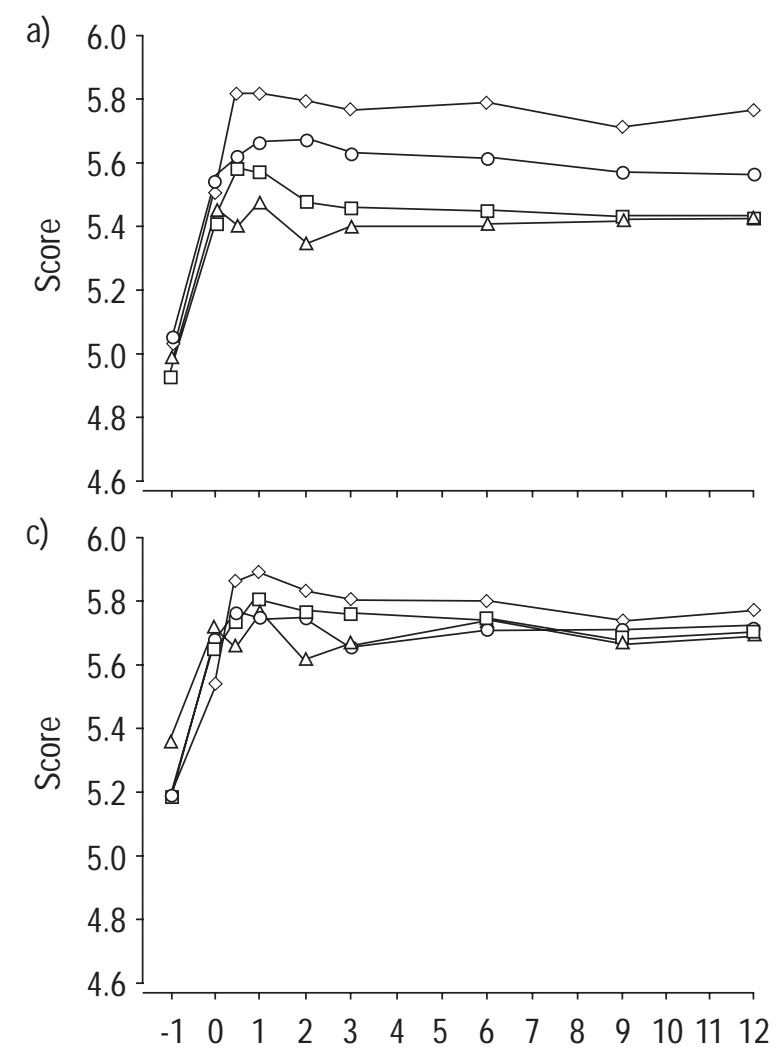

b)

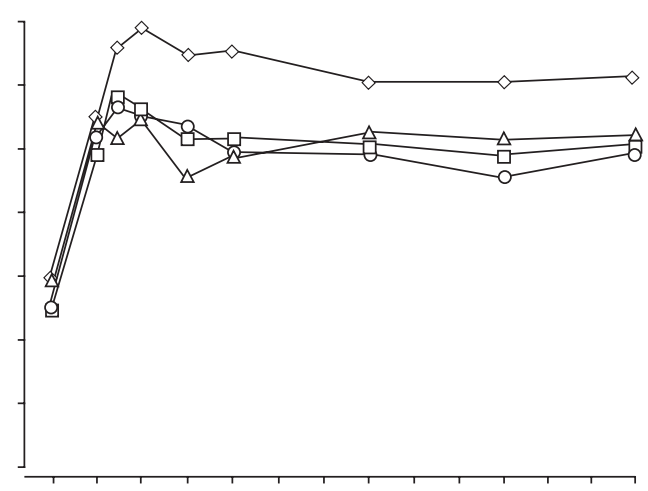

d)

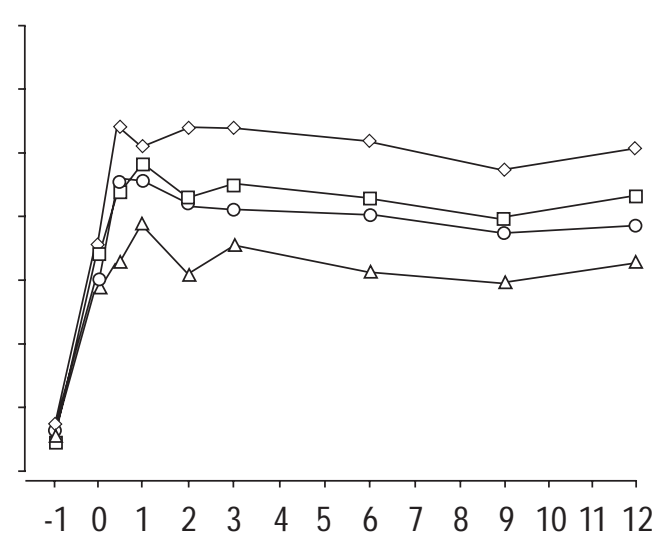

Fig. 2. - Asthma Quality of LIfe Questionnaire domains by treatment and visit: a) activity; b) symptoms; c) emotional function; and d) environmental exposure. Data are presented as means. $\triangle: 200 \mu \mathrm{g}$ budesonide daily (Bud200); $\bigcirc: 800 \mu \mathrm{g}$ budesonide daily (Bud800); $\square$ : Bud200+24 $\mu \mathrm{g}$ foroterol (F); $\diamond:$ Bud800+F.

magnitude $(\Delta \approx 0.5)$ that patients themselves consider important and can therefore be interpreted as clinically relevant [11].

Following randomization, only the Bud800+F group showed further improvement in AQLQ scores. The mean improvement of 0.2 was less than the minimal important difference of 0.5 [11]. In the past, such a change might have been dismissed as clinically irrelevant. However, more recent thinking has explored the inappropriateness of accepting all values above the minimal important difference and dismissing those below it. Patients are very heterogeneous in their responses to interventions and therefore it is important to look at not just the mean group value but also the distribution about the mean. New developments in interpretation methodology $[12,13]$ have allowed the presentation of the result of this study in a more clinically meaningful manner using the numberneeded-to-treat (NNT). The NNT for Bud800+F was calculated to be 11.9. This is the number of patients that would need to be treated with Bud800+F for one to have a clinically meaningful improvement in their asthma quality of life compared with use of other interventions. To many clinicians, not familiar with the interpretation of clinical trial results using the NNT, a value of 12 may seem rather high. When put in the context of other accepted clinical interventions, it is actually quite low. For instance, the use of statins for the prevention of stroke is advocated even though the NNT is $>200$ [14].

In all four treatment groups, the quality of life achieved 1 month after randomization was sustained throughout the 12 months of study. This suggests that there is no "honeymoon" period and that once improvements in HRQL are achieved, they do not deteriorate.

Although mean AQLQ scores were very similar in pattern to those seen for the clinical indices, the pattern within individual patients varied greatly, as is shown by the poor correlations between change in clinical indices and change in AQLQ score (table 3, fig. 4). Although some

Table 3. - Correlation between change $(\Delta)$ during randomized period for clinical variables and Asthma Quality of Life Questionnaire (AQLQ)

\begin{tabular}{lcccrr}
\hline & \multicolumn{5}{c}{$\Delta$ AQLQ Score } \\
\cline { 2 - 6 } & Overall & Symptoms & Activities & Emotions & Environment \\
\hline$\Delta$ Diary symptoms & -0.50 & -0.51 & -0.45 & -0.38 & -0.31 \\
$\Delta$ Rescue medication & -0.47 & -0.50 & -0.40 & -0.33 & -0.34 \\
$\Delta$ FEV1 \% pred & 0.14 & 0.16 & 0.12 & 0.09 & 0.12 \\
$\Delta$ Morning PEF & 0.39 & 0.37 & 0.37 & 0.27 & 0.30 \\
\hline
\end{tabular}

FEV1: forced expiratory volume in one second; PEF: peak expiratory flow. 


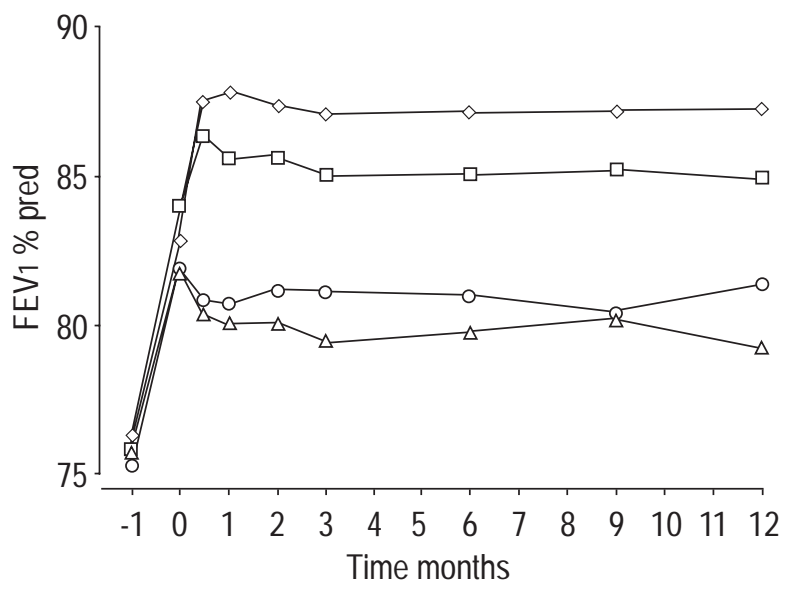

Fig. 3. - Forced expiratory volume in one second (FEV1) by treatment and visit. Data are presented as means. $\triangle: 200 \mu \mathrm{g}$ budesonide daily (Bud200); $\bigcirc: 800 \mu \mathrm{g}$ budesonide daily (Bud800); $\square$ : Bud200+24 $\mu \mathrm{g}$ foroterol $(\mathrm{F}) ; \diamond:$ Bud800+F.

loss of association will have been due to measurement noise, the range of changes was large (fig. 4) suggesting that some patients may experience relatively trivial changes in their clinical indices as a result of these interventions but experience large changes in their quality of life. In contrast, other patients may experience large changes in their clinical indices which do not manifest themselves as patient-perceived benefits. Similar relationships have been observed in short-term studies $[2,7,8$, $15]$, but this is the first observation of this pattern in a study with longer follow-up. These data emphasize that individual patient-perceived benefits from interventions cannot be derived from the usual clinical indices.

Both for overall quality of life and for each of the four domains, mean scores following randomization were high in all four treatment groups, suggesting that there was minimal quality of life impairment in most patients (fig. 2 and 3 ). Some patients in the higher-dose treatment groups, and particularly those in the Bud800+F group, may have reached maximum improvement and thus there may have been a ceiling effect, producing an underestimate of the

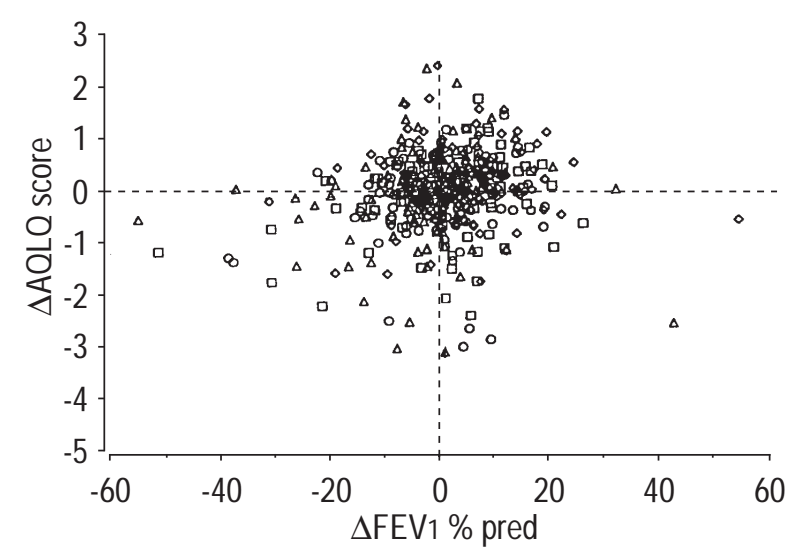

Fig. 4. - Change $(\Delta)$ in Asthma Quality of Life Questionnaire (AQLQ) overall score versus $\Delta$ forced expiratory volume in one second (FEV1) between randomization (visit 2 at 0 months) and the end of the study (visit 9 at 12 months). $\triangle: 200 \mu \mathrm{g}$ budesonide daily (Bud200); $\bigcirc: 800 \mu \mathrm{g}$ budesonide daily (Bud800); $\square$ : Bud200+24 $\mu \mathrm{g}$ formoterol (F); $\diamond$ : Bud800+F. Pearson correlation coefficient $=0.14(n=470)$. true treatment difference between the high- and the lowdose groups. In addition, there were more exacerbations treated with oral steroids in the lower-dose treatment group [1] which would also have tended to produce an underestimate of the true treatment difference between the high- and the low-dose treatment groups. Thus, the observed difference in quality of life between the treatment groups is probably conservative.

These results are valuable from a number of perspectives. They confirm that, although the patients' quality of life is improved by optimizing asthma control, no single conventional clinical indicator can capture this important component of patient management as effectively as a validated quality of life questionnaire. The largest improvements in quality of life occurred during the run-in period, when the patients received higher doses of inhaled budesonide in an effort to establish optimal asthma control prior to randomization. Once on randomized treatment, the best degree of asthma control, as measured by symptoms, lung function and fewer exacerbations, were achieved in patients taking Bud800+F [1], who were the only group who had an additional improvement in AQLQ scores. This suggests that the AQLQ is as responsive as the conventional clinical variables considered important in measuring asthma control. This study, for the first time, shows that quality of life improvements persist as long as the benefits of treatment persist, for up to $1 \mathrm{yr}$ in the present study. Measuring asthma-specific quality of life does not remove the need for the more conventional variables in studies of asthma management, as these, particularly FEV1, are valuable in determining the degree of pulmonary impairment and establishing asthma severity. However, the AQLQ provides a new dimension and gives additional information on the potential benefits of treatment. It enhances rather than replaces the other variables usually measured.

In conclusion, the results of this study show that the combination of the higher dose of budesonide and formoterol provides the greatest improvement in asthma-specific quality of life. They also show that improvements in quality of life are sustained in a similar manner to improvements in conventional clinical indices and that there is no evidence of deterioration once the initial benefits have become established. Finally, they show that the long-term benefits that patients themselves experience, in terms of their physical, social, occupational and emotional functioning, cannot be inferred from conventional clinical indices of asthma control and severity; they must be measured directly using validated quality of life questionnaires.

Acknowledgements. The following physicians, listed according to country, enrolled patients: Belgium/Luxembourg: W. DeBacker, M. Decramer, PM. Mengeot, J.P. Parini, L. Siemons, J. Verhaert, W. Vinken; Canada: M. Alexander, J. Bouchard, A. Day, A. Knight, J-L. Malo, D. Marciniuk, J.G. Martin, S. Peters, B. Sanders, B. Sproule, D. Stubbing; the Netherlands: A. Baas, T.A. Bantje, J. Creemers, H. Sinninghe Damsté, W. Evers, S. Gans, A. Greefhorst, H. Hassing, F. Maesen, M.J. Möllers, H.R. Pasma, Z. Pelikan, P.E. Postmus, J. Prins, B.M. Santana, M. Schrijver, A.P. Sips, R. Stallaert, L. van der Maas, A.J. van Harreveld; UK: G. Basran, L.M. Campbell, D. Franklin, G.J. Gibson, R.C. Joshi, A. Knox, A.B. Maclean, R. Scott, R. Smith, A. Tattersfield, J.P. Vernon. 


\section{References}

1. Pauwels RA, Löfdahl CG, Postma DS, et al. Effect of inhaled formoterol and budesonide on exacerbations of asthma. N Engl J Med 1997; 337: 1405-1411.

2. Juniper EF, Johnston PR, Borkhoff CM, Guyatt GH, Boulet LP, Haukioja A. Quality of life in asthma clinical trials: comparison of salmeterol and salbutamol. $A m J$ Respir Crit Care Med 1995; 151: 66-70.

3. Wenzel SE, Lumry W, Manning M, et al. Efficacy, safety, and effects on quality of life of salmeterol versus albuterol in patients with mild to moderate persistent asthma. Annals Allergy Asthma Immunol 1998; 80: 463-470.

4. Kemp JP, Cook DA, Incaudo GA, et al. Salmeterol improves quality of life in patients with asthma requiring inhaled corticosteroids. J Allergy Clin Immunol 1998; 101: 188-195.

5. Mahajan P, Okomoto LJ, Schaberg A, Kellerman D, Schoenwetter WF. Impact of fluticasone propionate powder on health-related quality of life in patients with moderate asthma. J Asthma 1997; 34: 227-234.

6. Noonan M, Chervinsky P, Busse WW, et al. Fluticasone proprionate reduces oral prednisone use while it improves asthma control and quality of life. Am J Respir Crit Care Med 1995; 152: 1467-1473.

7. Reese PR, Mahajan P, Woodring A. Salmeterol/fluticasone propionate combination product improves quality of life in asthma patients. Eur Respir J 1998; 12: 35S.
8. Rutten-van Molken MPMH, Clusters F, Van Doorslaer EKA, et al. Comparison of performance of four instruments in evaluating the effects of salmeterol on asthma quality of life. Eur Respir J 1995; 8: 888-898.

9. Juniper EF, Guyatt GH, Epstein RS, Ferrie PJ, Jaeschke R, Hiller TK. Evaluation of impairment of health-related quality of life in asthma: development of a questionnaire for use in clinical trials. Thorax 1992; 47: 76-83.

10. Juniper EF, Guyatt GH, Ferrie PJ, Griffith LE. Measuring quality of life in asthma. Am Rev Respir Dis 1993; 147: 832-838.

11. Juniper EF, Guyatt GH, Willan A, Griffith LE. Determining a minimal important change in a disease-specific quality of life instrument. J Clin Epidemiol 1994; 47: 81-87.

12. Juniper EF. The interpretation of clinical trial data. (Editorial) J Allergy Clin Immunol 1998; 102: 16-17.

13. Guyatt GH, Juniper EF, Walter SD, Griffith LE, Goldstein RS. Interpreting treatment effects in randomised trials. $\mathrm{Br}$ Med J 1998; 316: 690-693.

14. Crouse JR III, Byington RP, Hoen HM, Furberg CT. Reductase inhibitor monotherapy and stroke prevention. Arch Intern Med 1997; 157: 1305-1310.

15. Van der Molen T, Postma DS, Schreurs AJ, Bosveld HE, Sears MR, Meyboom de J. Discriminative aspects of two generic and two asthma-specific instruments: relation with symptoms, bronchodilator use and lung function in patients with mild asthma. Qual Life Res 1997; 6: 353-361. 